\title{
Diagnosis of High-risk Gestational Diabetes Mellitus
}

${ }^{1}$ Department of Obstetrics and Gynecology, Nepal Medical College and Teaching Hospital, Attarkhel, Jorpati, Kathmandu, Nepal.

Correspondence:

Dr. Sumi Singh Email: sumi1995@gmail.com

Gestational diabetes mellitus (GDM) can be defined as any degree of glucose intolerance with onset or first recognition during pregnancy. Screening for GDM is done usually at 24-28 weeks of gestation. In this case a 27-year-old primigravida who was diagnosed as GDM after a one step approach at 22 weeks of pregnancy. Institution of management early by the help of one step diagnosis was associated with successful outcome. The case highlights the importance of diagnosing GDM early especially in developing countries where resources are limited.

Keywords: Diabetes mellitus; pregnancy-induced; gestational diabetes.

Submitted: May 11, 2021 Accepted: June 18, 2021

\section{INTRODUCTION}

Approximately $15 \%$ percent of all pregnancies are complicated by gestational diabetes mellitus (GDM). ${ }^{1}$ Detection should be done during the 24-28 weeks of gestation in which there is threefold rise in maternal insulin output to maintain euglycaemia. Mothers with deficient insulin reserve become glucose intolerant at this time. ${ }^{2}$ There are two diagnostic approaches; one-step approach in which an oral glucose tolerance test (OGTT) done without prior glucose challenge test and in the next two-step approach we perform glucose challenge test, then measure fasting plasma glucose followed by OGTT to diagnose GDM. ${ }^{3}$ The one-step approach is done to high-risk pregnant women.

Citation: Singh S. Diagnosis of high-risk gestational diabetes mellitus. Nepal J Health Sci. 2021 Jan- Jun;1(1): 57-59

\section{CASE REPORT}

A 27-year-old primigravida female from rural EasternNepal presented to the centre at 24 weeks of gestation according to her last menstrual period, with chief complaints of increased frequency of urination for 10-12 times in a day and increased appetite for last three weeks. She was perceiving good foetal movements. She had strong family history of diabetes mellitus in both her parents. She did not consume alcohol. Her body mass index was $26.9 \mathrm{~kg} / \mathrm{m}^{2}$ and blood pressure was 128 by $78 \mathrm{~mm} \mathrm{Hg}$. To screen her, a 75 grams of OGTT was performed. Her fasting blood glucose was $106 \mathrm{mg} / \mathrm{dl}$ and two hours after glucose administration blood glucose level was $162 \mathrm{mg} / \mathrm{dl}$. Based on World Health Organisation (WHO) criteria as she was a high-risk patient, she was diagnosed with gestational diabetes mellitus. ${ }^{3}$ This was the first time she approached for medical attention. Basic routine antenatal care (ANC) investigations were conducted and were normal. Ultrasound findings estimated foetal weight of 233 grams. She was admitted with general random blood sugar (GRBS) ${ }^{5}$ profile monitoring per day, daily iron and calcium supplementation and was started on oral hypoglycaemic medication metformin $500 \mathrm{mg}$ per oral twice a day. 
Table 1: General random blood sugar profile following admission.

\begin{tabular}{|l|l|l|l|l|l|}
\hline & Fasting & Pre-lunch & Post-lunch & Pre-dinner & Post dinner \\
\hline 1st day of admission & - & - & - & $76 \mathrm{mg} / \mathrm{dl}$ & $186 \mathrm{mg} / \mathrm{dl}$ \\
\hline 2nd day of admission & $135 \mathrm{mg} / \mathrm{dl}$ & $82 \mathrm{mg} / \mathrm{dl}$ & $96 \mathrm{mg} / \mathrm{dl}$ & $84 \mathrm{mg} / \mathrm{dl}$ & $126 \mathrm{mg} / \mathrm{dl}$ \\
\hline 3rd day of admission & $91 \mathrm{mg} / \mathrm{dl}$ & $107 \mathrm{mg} / \mathrm{dl}$ & $137 \mathrm{mg} / \mathrm{dl}$ & $116 \mathrm{mg} / \mathrm{dl}$ & $126 \mathrm{mg} / \mathrm{dl}$ \\
\hline
\end{tabular}

She was discharged on the third day of admission under oral hypoglycaemic agent and iron calcium supplementation. She was counselled about importance of exercise and diet control. She was also advised to perform foetal surveillance to monitor the growth of the baby. During her follow-up after one week following delivery her fasting blood glucose was $76 \mathrm{mg} / \mathrm{dl}$ and two-hour postprandial glucose level was $110 \mathrm{mg} /$ $\mathrm{dl}$, so she was continued in the oral antidiabetic agent. Following the course of pregnancy, total weight gain during the entire pregnancy was 12 kilograms. As she was a high risk GDM on oral hypoglycaemic agent. When she completed 38 weeks of pregnancy elective caesarean section was planned. A live and healthy female baby weighing 2700 grams was delivered. The baby had an uneventful neonatal course. The plasma glucose values returned normal by the next day and oral medication was stopped. She was asked to perform a 75 gram (gm) OGTT at six weeks postpartum and thereafter every three years. ${ }^{3}$ She was informed about her high risk of developing type 2 diabetes mellitus later and was advised to maintain normal body weight by regular physical activity and appropriate dietary modification.

\section{DISCUSSION}

Based on WHO criteria gestational diabetes mellitus should be diagnosed at any time in pregnancy if one or more of the following criteria are met, fasting plasma glucose between 92-135 mg/dl, one hour plasma glucose following a $75 \mathrm{gm}$ oral glucose load more than 180 $\mathrm{mg} / \mathrm{dl}$ and two hour of plasma glucose following a 75 gm oral glucose load between 153-199 mg/dl. Women with high risk of developing GDM include those who have a history of marked obesity, personal history of GDM, recurrent glycosuria, polycystic ovarian syndrome, and a strong family history of diabetes. They should undergo glucose testing as soon as possible during their ANC visit. ${ }^{3,4}$
According to American Diabetes Association, the diagnosis of GDM can be done by two approaches:

One-step approach: Perform a diagnostic 75 gm OGTT at 24th-28th week of gestation without prior $50 \mathrm{gm}$ GCT screening. The one-step approach can be applied to high-risk pregnant women of GDM, or all pregnant women not previously diagnosed with overt diabetes in well-conditioned medical institutions.

Two-step approach: Measure FPG (step 1); if FPG $\geq 5.1 \mathrm{mmol} / \mathrm{L}, \mathrm{GDM}$ can be diagnosed; if $4.4 \mathrm{mmol} / \mathrm{L}$ $\leq$ FPG $<5.1 \mathrm{mmol} / \mathrm{L}$, diagnostic 75-g OGTT (step 2) is followed to diagnose GDM or perform an initial screening by measuring the plasma or serum glucose concentration after a 50-g GCT (step 1) and perform a diagnostic OGTT (step 2) on that subset of women exceeding the glucose threshold value on the GCT; if $50 \mathrm{gm} \mathrm{GCT} \geq 11.1 \mathrm{mmol} / \mathrm{L}, \mathrm{FPG}$ is performed to diagnose GDM, if FPG value is normal, 75 gm OGTT should be underwent as soon as possible.

The presence of poorly controlled gestational diabetes mellitus it is associated with increase in risk of birth defects, spontaneous abortion and still births. ${ }^{4}$ This case highlights the importance of early diagnosis and balancing maternal diabetes in preventing adverse foetal outcome. Studies have shown that unbalanced maternal diabetes can lead to foetal macrosomia and hypertrophic cardiomyopathy. ${ }^{6}$ The aim is to maintain blood glucose between fasting 80-90 $\mathrm{mg}$ and post prandial is $110-129 \mathrm{mg} / \mathrm{dl}$ by dietary lifestyle modification or by hypoglycaemic agents. ${ }^{7}$ Screening for GDM is done between the 24th and 28th week of gestation. Diagnostic standard for GDM is when after 50 gm GCT the plasma glucose level is $\geq 140$ $\mathrm{mg} / \mathrm{dl}$ which is considered as the diagnostic cutpoint. The International Association of the Diabetes and Pregnancy Study Groups, American Diabetes Association, International Federation of Gynecology 
and Obstetrics and World Health Organization recommend the one-step Approach. ${ }^{8-10}$
Conflict of interest: None

\section{REFERENCES}

1. Ogurtsova K, da Rocha Fernandes JD, Huang Y, Linnenkamp U, Guariguata L, Cho NH, et al. IDF Diabetes Atlas: Global estimates for the prevalence of diabetes for 2015 and 2040. Diabetes Res Clin Pract. 2017 Jun;128:40-50. [PubMed | Full Text | DOI]

2. Buchanan TA, Xiang AH. Gestational diabetes mellitus. J Clin Invest. 2005 Mar;115(3):485-91. [PubMed | Full Text | DOI]

3. Diabetes Care Jan 2002, 25 (suppl 1) s94-s96. [Full Text | DOI]

4. Diagnostic criteria and classification of hyperglycaemia first detected in pregnancy: a World Health Organization Guideline. Diabetes Res Clin Pract. 2014 Mar;103(3):341-63. [PubMed | Full Text | DOI]

5. Cowie CC, Rust KF, Byrd-Holt DD, Eberhardt MS, Flegal KM, Engelgau MM, et al. Prevalence of diabetes and impaired fasting glucose in adults in the U.S. population: National Health and Nutrition Examination Survey 1999-2002. Diabetes Care. 2006 Jun;29(6):1263-8. [PubMed | Full Text | DOI]

6. Vincent M, Benbrik N, Romefort B, Colombel A, Bézieau S, Isidor B. Three patients presenting with severe macrosomia and congenital hypertrophic cardiomyopathy: a case series. J Med Case Rep. 2017 Mar 24;11(1):78. [PubMed | Full Text | DOI]

7. Mosammat Rashida Begum. GDM: Management Recommendation During Pregnancy, Gestational Diabetes - Causes, Diagnosis and Treatment, Luis SObrevia, IntechOpen. [Full Text]

8. International Association of Diabetes and Pregnancy Study Groups Consensus Panel, Metzger BE, Gabbe SG, Persson B, Buchanan TA, Catalano PA, Damm P, Dyer AR, Leiva Ad, Hod M, Kitzmiler JL, Lowe LP, McIntyre HD, Oats JJ, Omori Y, Schmidt MI. International association of diabetes and pregnancy study groups recommendations on the diagnosis and classification of hyperglycaemia in pregnancy. Diabetes Care. 2010 Mar;33(3):676-82. [PubMed | Full Text | DOI]

9. American Diabetes Association. Standards of medical care in diabetes--2012. Diabetes Care. 2012 Jan;35 Suppl 1(Suppl 1):S11-63. [PubMed | Full Text | DOI]

10. Hod M, Kapur A, Sacks DA, Hadar E, Agarwal M, Di Renzo GC, et al. The International Federation of Gynecology and Obstetrics (FIGO) Initiative on gestational diabetes mellitus: A pragmatic guide for diagnosis, management, and care. Int J Gynaecol Obstet. 2015 Oct;131 Suppl 3:S173-211. [PubMed | Full Text | DOI] 